\title{
Letters
}

Website: bmj.com

Email: letters@bmj.com

\section{Sentinel node biopsy for malignant melanoma}

\section{Having this biopsy gives psychological benefits}

EDITOR-The editorial by Thomas and Patocskai summarises the current state of sentinel lymph node biopsy for malignant melanoma. ${ }^{1}$ What the authors omitted to address was patients' perception of the procedure.

Anecdotal evidence suggests that patients with melanoma derive psychological benefit from having the procedure, regardless of the result. To investigate any such benefit our unit carried out a study looking at the acceptability and benefits of the procedure. A specially designed questionnaire was sent to 110 patients who had undergone the procedure between August 1997 and February 1999.

Ninety eight patients (89\%) replied, been positive (19/110). To study any time dependent trends the respondents were subdivided into three subgroups, depending on length of follow up (table). Most patients $(95 / 98)$ were glad that they had had the procedure, though the effects decreased with time (table). Overall 89 of the patients believed that they had gained some benefit from the biopsy, and 96 said that they would recommend it to other patients.

Most patients with melanoma undoubtedly derive at least short term psychological benefits from having a sentinel lymph node biopsy. This effect seems to be independent of the result of the biopsy itself. The decreased reassurance with time may simply represent a time dependent factor but might be due to the frequent clinic visits and additional biopsies of suspicious lesions, which cause increased anxiety in patients with melanoma. ${ }^{2}$

The procedure has high patient acceptability and offers patients a proactive option in addition to regular clinic reviews after initial diagnosis. It does not, however, seem a clinical trial. ${ }^{13}$ Midlands B71 4HJ sukhr@hotmail.com Birmingham B29 6JD (1 July.) Oncol 1993;5:174-80. 1999;189:214-23 including all those in whom the result had

greatly to influence patients' worries about being "cured" or fully enable patients to plan for the future. The small psychological benefit shown in our study cannot be used to justify routine sentinel lymph node biopsy in patients with melanoma. The cost and morbidity of this procedure must be balanced by proved survival benefit. We agree with others that until such benefit is shown, sentinel lymph node biopsy should be offered only in a multidisciplinary setting as part of

S S Rayatt specialist registrar in plastic surgery Department of Plastic Surgery, Sandwell Healthcare NHS Trust, West Bromwich, West

S P Hettiaratchy specialist registrar in plastic surgery Department of Plastic Surgery, Selly Oak Hospital,

1 Thomas MJ, Patocskai EJ. The argument against sentine node biopsy for malignant melanoma. BMJ 2000;321:3-4

2 Baughan CA, Hall VL, Leppard BJ, Perkins PJ. Follow-up in stage I cutaneous malignant melanoma: an audit. Clin

3 Morton D, Chan A. Current status of intraoperative lymphatic mapping and sentinel lymphadenectomy fo melanoma: is it standard of care? J Am Coll Surg

\section{What is a prognosis worth?}

EDitor-Thomas and Patocskai seem to dismiss the value of sentinel node sampling as a prognostic tool because so little can be done to modify the natural course of the disease once micrometastases are evident. ${ }^{1}$ They seem not to appreciate that patients may want to be given as accurate a prognosis as possible despite knowing that effective treatment may not be available if more widespread disease is diagnosed.

Last month my intermediate thickness melanoma was excised. I was aware that a negative result on sentinel lymph node biopsy would increase my five year survival chances to above $90 \%$ and that a positive

Benefits of sentinel node biopsy to 98 patients with malignant melanoma. Values are numbers (percentages) of patients

\begin{tabular}{lccccc} 
& \multicolumn{3}{c}{ Follow up } & \\
\cline { 2 - 5 } Benefit & $\begin{array}{c}\mathbf{6} \text { months } \\
(\mathbf{n = 5 4 )}\end{array}$ & $\begin{array}{c}\mathbf{7 - 1 2} \text { months } \\
(\mathbf{n = 3 3 )}\end{array}$ & $\begin{array}{c}\mathbf{1 3 - 1 8} \text { months } \\
(\mathbf{n = 1 1 )}\end{array}$ & $\begin{array}{c}\text { Overall } \\
(\mathbf{n = 9 8 )}\end{array}$ & $\begin{array}{c}\text { P value for } \\
\text { trend }^{*}\end{array}$ \\
\hline Peace of mind & $50(92)$ & $27(81)$ & $7(63)$ & $84(86)$ & 0.03 \\
\hline Planning for future & $29(53)$ & $13(39)$ & $4(36)$ & $46(47)$ & 0.23 \\
\hline Well looked after & $51(94)$ & $26(79)$ & $7(63)$ & $85(87)$ & 0.01 \\
\hline Reassured of no spread & $42(78)$ & $25(76)$ & $4(36)$ & $71(72)$ & 0.02 \\
\hline Cured & $22(41)$ & $9(27)$ & $2(20)$ & $33(34)$ & 0.2 \\
\hline
\end{tabular}

${ }^{*}$ Analysed by $\chi^{2}$ test. result would reduce this to around $50 \%$. was also aware that I had between a $7 \%$ and a $20 \%$ chance of the result of the biopsy being positive. These were statistics that my 11 year old daughter could understand.

If my mother had just had Huntington's disease diagnosed my request for a prognostic test would be unlikely to be turned down on the basis that the disease is untreatable. Perhaps there should be a fuller debate about the amount of money the NHS is prepared to spend on establishing prognoses.

Sarah Wookey general practitioner West Bar Surgery, Banbury OX16 9SF sarahw@andromedalight.co.uk

1 Thomas MJ, Patocskai EJ. The argument against sentinel node biopsy for malignant melanoma. BMJ 2000;321:3-4. (1 July.)

Biopsy helps define population who will benefit

EDITOR-Thomas and Patocskai believe that all patients undergoing sentinel node biopsy for malignant melanoma should be confined to trials. ${ }^{1}$ All those who carry out the technique support this, but at present no large, prospective, randomised trial exists for these patients. The multicentre sentinel lymphadenectomy trial has closed. ${ }^{2}$ A trial by the European Organisation for the Research and Treatment of Cancer started in September this year. A working party of

\section{Advice to authors}

We prefer to receive all responses electronically, sent either directly to our website or to the editorial office as email or on a disk. Processing your letter will be delayed unless it arrives in an electronic form.

We are now posting all direct submissions to our website within 24 hours of receipt and our intention is to post all other electronic submissions there as well. All responses will be eligible for publication in the paper journal.

Responses should be under 400 words and relate to articles published in the preceding month. They should include $\leqslant 5$ references, in the Vancouver style, including one to the BMJ article to which they relate. We welcome illustrations.

Please supply each author's current appointment and full address, and a phone or fax number or email address for the corresponding author. We ask authors to declare any competing interest. Please send a stamped addressed envelope if you would like to know whether your letter has been accepted or rejected.

Letters will be edited and may be shortened.

bmj.com

letters@bmj.com 
the Melanoma Study Group (UK) is going through the approval stage for a multicentre prospective trial in the United Kingdom. With such a limited number of centres undertaking the technique, however, numbers will be small.

The authors quote the American intergroup melanoma trial, which showed a survival benefit (in patients aged under 60, with tumours of 1.1-2.0 $\mathrm{mm}$ and no ulceration) in those who underwent wide local excision and elective lymph node dissection versus those who underwent wide local excision alone. ${ }^{3}$ The World Health Organization melanoma programme (trial 14) confirmed a survival benefit in men with melanoma less than $4.0 \mathrm{~mm}$ who underwent wide local excision and elective lymph node dissection compared with those who underwent wide local excision alone $(\mathrm{P}=0.03)$.

A further update to this latter trial has been published. After an eight year follow up the five year survival rate in patients with occult nodal metastases was $48.2 \%$ in those with elective lymph node dissection compared with $26.6 \%$ in those in whom wide local excision and therapeutic (delayed) lymph node dissection was carried out. ${ }^{5}$ The belief is that sentinel node biopsy will help us define the population who will benefit. This alone must surely justify the inclusion of this valuable investigation in all future health service funding proposals.

With 300 sentinel node biopsies undertaken in the Melanoma Unit at St George's Hospital, we have not seen any increased evidence of entrapment. Several patients have developed local recurrent disease after sentinel node biopsy, but the numbers have not changed from the days of wide local excision alone.

Barry Powell consultant plastic surgeon Melanoma Unit, St George's Hospital, London SW17 0QT

bpowell@sghms.ac.uk

1 Thomas MJ, Patocskai EJ. The argument against sentine node biopsy for malignant melanoma. BMJ 2000;321:3-4 node biop

2 Morton DL, Thompson JF, Essner R, Elashoff R, Stern SL, Niewig $\mathrm{O}$, et al. Validation of the accuracy of intraoperative lymphatic mapping and sentinel lymphadenectomy for early stage melanoma: a multicentre trial. Ann Surg 1999;230:453-65

3 Balch CM, Soong SJ, Bartolucci AA, Unst NM, Karakousis CP, Smith TJ, et al. Efficacy of an elective regional lymph node dissection of 1-4 mm thick melanomas for patient 60 years and younger. Ann Surg 1996;224:255-66.

4 Cascinelli N. The role of clinical trials in assessing optima treatment of cutaneous melanoma not extending beyond the regional nodes. Eur J Surg Oncol 1996;22:123-33.

5 Cascinelli N, Morabito A, Santinami M, MacKie RM, Bell F. Immediate or delayed dissection of regional nodes in patients with melanoma of the trunk: a randomised trial. Lancet 1998;351:793-6.

\section{Biopsy discriminates between stages of disease and prognosis}

EDITOR-Thomas and Patocskai's statements in their editorial should be carefully considered. ${ }^{1}$ Currently there is no effective adjuvant therapy for patients with stage III melanoma, and less than a fifth of patients in the United Kingdom who are eligible for clinical trials are entered into them. Sentinel node biopsy will become a useful discriminator between stages II and III disease and should be considered before entry into a clinical trial.
The incidence of melanoma in the United Kingdom is low (4000 cases), and the disease affects younger people. A prognosis of $93 \%$ compared with $67 \%$ will be of immense importance to them. In this era of informed consent, I wonder how many of the authors' patients are informed that there is an investigation that would potentially up-stage the disease in a fifth of those patients who have a melanoma $>1 \mathrm{~mm}$ thick. This ability to stratify patients prognostically may not be important to the authors, but patients who have this information can make decisions about their future. All the patients in trials that colleagues and I have participated in accepted this procedure despite being informed of the lack of effective treatments available and the inaccuracies in the technique.

The authors state that sentinel node biopsy has no therapeutic value, but they fai to acknowledge that the technique is effective in staging a patient's disease and identifying those lymph node areas at risk for disease. ${ }^{2}$ Although they do not offer sentinel node biopsies, the newer technique that they mention-the reverse transcriptase polymerase chain reaction-is experimental and expensive, has a high rate of false positive results, ${ }^{3}$ and does not have any therapeutic value.

Sentinel lymph node biopsy is widely available in the United States, Australia, and elsewhere in Europe. The World Health Organization has recommended that it become a standard procedure for patients with melanoma. Information regarding sentinel node biopsy is freely available and accessible by the general public, who will expect their specialist to give them the opportunity to be involved in the decisions regarding their management and prognosis.

In the United Kingdom only a few centres offer sentinel node biopsy. All patients at the Radcliffe Infirmary are entered into ongoing clinical trials in the United Kingdom and the rest of Europe. Those centres that offer this service will continue to be at the forefront of all current ideas and look forward to the support from those units that do not offer this procedure.

M Dalvi Humzah consultant plastic surgeon

Department of Plastic and Reconstructive Surgery,

Radcliffe Infirmary, Oxford OX2 6HE

dalvi.humzah@nds.ox.ac.uk

1 Thomas MJ, Patocskai EJ. The argument against sentine node biopsy for malignant melanoma. BMJ 2000;321:3-4. (1 July.)

2 Norman J, Cruse CW, Espinosa C, Cox C, Berman C, Clark

R, et al. Redefinition of cutaneous lymphatic drainage with $\mathrm{R}$, et al. Redefinition of cutaneous lymphatic drainage with
the use of lymphoscintigraphy for malignant melanoma the use of lymphoscintigraphy for malignant melanoma. Am J Surg 1991;162:432-7.

3 Van Diest PJ. Histological workup of sentinel lymph nodes:

how much is enough? J Clin Pathol 1999;52:871-3.

\section{Staging procedures predict outcome and} identify patients needing further treatment

EDITOR-Thomas and Patocskai accept the value of sentinel node biopsy as a staging procedure for melanoma but then argue against its use on the grounds that its effect on survival is uncertain. ${ }^{1}$ This of course is true, but staging procedures are not supposed to affect survival: they predict outcome, identify those patients who require further treatment, and reassure those who do not.

In recognition of this, the most recent staging system published by the American Joint Committee on Cancer includes separate category for patients with micrometastatic disease in the sentinel node, pathological stage IIIIa. In addition, the president of the World Health Organization's melanoma programme has stated that sentinel node biopsy currently represents the standard of care in the management of patients with primary melanoma. ${ }^{3}$ Thomas and Patocskai may see no advantage in staging disease in patients with melanoma, but theirs is a minority view worldwide.

The main issue is not in fact sentinel node biopsy but the lack of consensus as to the best management of patients with stage III melanoma. Even so, high dose adjuvant therapy with interferon alfa $2 \mathrm{~b}$ is licensed in the United Kingdom for the treatment of high risk melanoma, including patients with stage III disease, so this can be offered to patients with positive results on sentinel node biopsy.

In addition, knowing the patient's lymph node state is a prerequisite for obtaining useful information from clinical trials, and one could argue that new trials of clinical stage $\mathrm{Ib} / \mathrm{II}$ melanoma should not be permitted unless patients are stratified according to their lymph node state. In particular, it would seem pointless undertaking wide and often mutilating surgical excisions of primary lesion in patients who are already positive on sentinel node biopsy.

Thomas and Patocskai's editorial verdict is that no patient should undergo sentinel node biopsy unless he or she is entered into a clinical trial. This seems rather extreme. Surely the sensible approach is to offer sentinel node biopsy as a staging procedure in those centres that are skilled and experienced in the technique, and then to discuss with the patient the options available in the event that the result is positive. Clinical trials are crucial provided the patient is willing to embark on a study with an observational arm. What is not acceptable is for centres that do notrely on sentinel node biopsy to dictate to other centres how their patients should be managed.

Robin Russell-Jones director, Skin Tumour Unit russelljones@btinternet.com

Eduardo Calonje director, diagnostic dermatopathology

St John's Institute of Dermatology, St Thomas's Hospital, London SE1 7EH

Ciaran Healy consultant plastic surgeon, department of plastic surgery

Michael Doherty consultant nuclear physician department of nuclear medicine

St Thomas's Hospital, London SE1 7EH

Peter Butler consultant plastic surgeon, department of plastic surgery

Alison Jones consultant oncologist, department of clinical oncology

Sean Whittaker consultant dermatologist, department of dermatology

Royal Free Hospital, London NW3 2PF

Katharine Acland consultant dermatologist

Department of Dermatology, Hammersmith

Hospital, London W12 0NN 
1 Thomas MJ, Patocskai EJ. The argument against sentinel node biopsy for malignant melanoma. BMJ 2000;321:3-4 (1 July.)

2 Balch C, Buzaid A, Atkins M, Cascinelli N, Coit D, Fleming I, et al. A new American Joint Committee on Cancer staging system for cutaneous melanoma. Cancer 2000;88:1484-91.

3 WHO declares lymphatic mapping to be the standard of care for melanoma. Oncology 1999;13:288.

4 Kirkwood J, Strawderman M, Ernstoff M, Smith T, Borden E Blum R. Interferon alfa $2 \mathrm{~b}$ adjuvant therapy of high risk resected cutaneous malignant melanoma: the Eastern Oncology Group trial EST 1684. J Clin Oncol 1996;14:7-17.

\section{Authors' reply}

EDITOR-Several points in these letters need to be addressed. Is the value of sentinel node biopsy as a prognostic test sufficient for it to be performed despite the lack of effective adjuvant therapy in patients in whom the result is positive? Obviously some psychological benefit is incurred from being placed in a group with a good prognosis-survival is $93 \%$ at three years for patients in whom the result is negative.

But even the worst case scenario (having positive sentinel nodes) represents $67 \%$ survival at three years. For some people this $26 \%$ difference may be important enough for them to alter important decisions in their lives, even with the possibility of false negative results and the knowledge that a negative sentinel node does not guarantee the absence of systemic disease. Others may be happy to accept the statistics generated from other prognostic factors, including tumour depth and ulceration, without undergoing sentinel node biopsy. We agree that a debate about the amount of money that the NHS is prepared to spend on sentinel node biopsy as a means of more precise staging would be welcome

It is correct that the American Joint Committee on Cancer's proposed classification has taken into account micrometastases in the staging of melanoma, but the micrometastases are defined as "diagnosed after elective or sentinel lymphadenectomy." Surely this does not justify funding for elective lymph node dissection by the NHS as Powell seems to believe that the inclusion of this subgroup justifies funding for sentinel node biopsy.

The World Health Organization has recommended that sentinel node biopsy should become standard procedure for patients with tumour thickness $>1 \mathrm{~mm}$. But Morton (one of the main exponents of the technique) and Chan reserve their opinion until the trials of efficacy are completed. ${ }^{2}$ We agree with this.

Russell-Jones et al may well see an immediate need for sentinel node biopsy, to avoid "wide and often mutilating surgical excisions of primary lesion." Current practice, however, dictates smaller resection margins, with no more than a $2 \mathrm{~cm}$ margin for melanomas $>1 \mathrm{~mm}$. High dose interferon alpha $2 \mathrm{~b}$ has a high toxicity rate and has not shown a survival advantage in patients with metastatic nodes. ${ }^{3}$ Whether it should be offered as standard treatment for patients at high risk of relapse is still a matter of debate.

Our editorial did not state that we perform or advocate reverse transcriptase polymerase chain reaction in blood. But it is important to be aware that different techniques are being developed to detect circulating tumour cells. The prognostic implications of these techniques as compared to sentinel node biopsy are not yet defined.

A consensus on sentinel node biopsy will be achieved when an adjuvant treatment that improves overall survival is developed or it has been shown that complete node dissection in patients with positive sentine nodes is of benefit in terms of either overal survival or local control. Those who expound the use of sentinel node biopsy outside clinical trials need to be reminded that the main aim of staging cancer is to direct treatment.

J Meirion Thomas consultant surgeon josephmeirion.thomas@rmh.nthames.nhs.uk

Erica J Patocskai research fellow

Melanoma and Sarcoma Unit, Royal Marsden Hospital, London SW3 6JJ

1 Balch $\mathrm{C}, \mathrm{Buzaid} \mathrm{A}$, Atkins $\mathrm{M}, \mathrm{Cascinelli} \mathrm{N}$, Coit D, Fleming I, et al. A new American Joint Committee on Cancer staging system for cutaneous melanoma. Cancer 2000;88:1484-91

2 Morton D, Chan A. Current status of intraoperative lymphatic mapping and sentinel lymphadenectomy for melanoma: is it standard of care? J Am Coll Sur 1999;189:214-23

Kirkwood JM, Ibrahim JG, Sondak VK, Richards J, Flaherty LE, Ernstoff MS, et al. High- and low-dose interfero alfa-2b in high-risk melanoma: first analysis of intergroup

\section{Incidence of congenital rubella in Greece}

EDITOR-Giannakos et al present data on the rubella epidemic in Greece in 1999. They also question the main conclusion of our paper on the 1993 rubella epidemic in Greece that the incidence of the congenita rubella syndrome had increased in 1993 compared with the pre-vaccination period owing to inconsistent immunisation practices. $^{2}$

Their first (indirect) argument is that their data on the 1999 epidemic "do not show a real increase in the incidence of congenital rubella." This is clearly irrelevant as our conclusion pertained to the 1993 epidemic. Besides, the rubella epidemic in 1999 was smaller than that in 1993 by a factor of 5.3 in terms of reported rubella cases (Y Tselentis, personal communication).

They comment that our data "do not confirm an increase because data from an active, retrospective surveillance system in 1993-4 were compared with poor quality pre-existing data from passive surveillance." Nevertheless, as mentioned in our paper on $\mathrm{p}$ 1465 , an active investigation carried out by the Ministry of Health to identify cases of the congenital rubella syndrome after the large rubella epidemic of 1983 (the largest recorded in Greece) identified only sporadic cases of the syndrome. ${ }^{3}$ The fact that an active investigation was carried out in 1983 by the ministry in key Greek hospitals was confirmed by its then director of public health ( $\mathrm{T}$ Stefanou, personal communication)

The investigation that we carried out after the 1993 epidemic was probably more extensive than that conducted 10 years earlier. ${ }^{2}$ We identified 25 cases of the congenital rubella syndrome, with a substantial increase in age at infection. ${ }^{2}$ Twenty cases were admitted to one of the two major paediatric hospitals in Athens, two were admitted to a major hospital in Thessaloniki, and another two were diagnosed from the results of tests by a central reference laboratory. ${ }^{4}$ It is thus highly unlikely that most cases of the congenital rubella syndrome had been missed in the 1983 investigation.

This is in accordance with the findings of a parallel study that we carried out retrospectively in the department of infectious diseases of one of the two major paediatric hospitals in Athens (Agia Sophia) and in the neonatal unit of the other (A Kyriakou): two sporadic cases of the congenital rubella syndrome were admitted during 1983-92 (including the epidemic years 1983 and 1986) and 11 in $1993 .^{45}$

Takis Panagiotopoulos senior researcher tpan@ath.forthnet.gr

Ioanna Antoniadou senior researcher

\section{Eleni Valassi-Adam director}

Department of Social Paediatrics, Institute of Child Health, Agia Sophia Children's Hospital, 11527 Athens, Greece

1 Giannakos G, Pirounaki M, Hadjichristodoulou C. Incidence of congenital rubella in Greece has decreased. BMJ 2000;320:1408. (20 May)

2 Panagiotopoulos T, Antoniadou I, Valassi-Adam E. Increase in congenital rubella occurrence after immunisation in Greece: retrospective survey and systematic review. BMJ 1999; 319:1462-6.

3 Hellenic Ministry of Health and Social Security, Directorate of Public Health. Circular December 1983. (A1/12605. [In Greek.]

4 Panagiotopoulos T, Antoniadou I, Valassi-Adam E. Congenital rubella syndrome epidemic in Greece in 1993. A report of 25 confirmed cases. Paediatriki 1997;60:582-9. [In Greek.]

5 Panagiotopoulos T, Papademetriou M, Delagrammatikas $\mathrm{H}$. Congenital rubella in a neonatal unit in Athens, 1983-1994. Paediatriki 1998;61:37-40. [In Greek.]

\section{Water fluoridation has not been banned anywhere}

EDITOR-I was surprised and disappointed to read Payne's article on water fluoridation. ${ }^{1}$ The only change with regard to fluoridation in Ireland is that the minister has established a forum on fluoridation. This is in line with similar action by governments in other countries where fluoridation is practised. The terms of reference for the review are to consider the fluoridation of public piped water supplies and the programme of research being undertaken on behalf of the health boards in the area, and to report to the minister.

Over the past two years or so opponents of fluoridation in Ireland have targeted local councils and the news media in a relentless campaign based on scaremongering and misinformation. Some local councils have been alarmed by allegations of potential adverse health effects from fluoridation and have, quite properly, expressed their concerns to the government Department of Health and Children. In announcing the setting up of the forum the minister said that he was conscious of concerns being expressed in the media by opponents of 
water fluoridation and was anxious to give these groups a full opportunity to have their concerns heard and answered through the forum.

I was surprised, however, to see the many unfounded antifluoridation allegations repeated, apparently unquestioned, in the $B M J$. Examples include the statement that fluoridation has been "banned" in several European counties, which is loaded with antifluoridation bias. No country legislates to prevent fluoridation. Payne implies throughout the article that there is significant controversy within the scientific community about the long term health effects of water fluoridation. This is quite simply not the case; every reputable medical and scientific organisation that has considered the issue agree that water fluoridation is a safe and effective public health measure.

Water fluoridation is the single most effective public health measure available to reduce the prevalence and severity of tooth decay, and hence to reduce inequalities in dental health. In the almost 40 years since its widespread implementation in Ireland, fluoridation has made a major contribution to the oral health of the Irish population. As a result the oral health status of Irish children and adults is now among the best in Europe.

M A Lennon professor of dental public health University of Liverpool, Department of Clinical Dental Sciences, Liverpool L69 3GN malen@liv.ac.uk

1 Payne D. Ireland might relax fluoride rules. $B M$ J 2000;320:1560. (10 June.)

\section{Malaria affects children and pregnant women most}

EDITOR-Croft has written about preventing malaria in travellers. ${ }^{1}$ Malaria is more common and more severe in children and pregnant women, and clear recommendations regarding prevention in these groups are crucial.

Case reports of potential toxicity caused by diethyltoluamide in children and pregnant women are poorly documented, and in most cases use of the repellent was excessive. A retrospective study of 9086 reports of diethyltoluamide toxicity found that children were no more likely to develop adverse effects than adults. ${ }^{2}$ Almost two thirds of those exposed had no adverse effects, and $99 \%$ had no long term sequelae. Diethyltoluamide is the most effective insect repellent and should be recommended for children and adults, including pregnant women, in concentrations of up to $30 \%$.

Croft does not provide sufficient information about the studies concerning use of mefloquine in childhood and pregnancy. ${ }^{34}$ Luxemburger et al documented the efficacy and tolerability of mefloquine in 417 children aged between 3 months and 5 years. ${ }^{3}$ The only side effects were gastrointestinal, the major one being early vomiting. This is not a substantial problem, however, in children given prophylactic doses. Serious neuropsychiatric adverse effects have not been described in children given mefloquine for prophylaxis.

One of the preliminary findings from Nosten et al's study in pregnancy was a significant excess of stillbirths in women given mefloquine, although this was not borne out in the overall analysis. ${ }^{4}$ Moreover, only women in the second and third trimesters of pregnancy were included. Subsequent studies of the use of mefloquine beyond the first trimester have had conflicting results; some data suggest that mefloquine may be safe throughout pregnancy. The excretion into breast milk is minimal.

In conclusion, mefloquine is an acceptable choice for prophylaxis in children from 3 months of age (weighing over $5 \mathrm{~kg}$ ). Whether it is safe in pregnancy remains unclear, although many authorities recommend its use for prophylaxis beyond the first trimester. It is safe for use during lactation.

Doxycycline forms a stable calcium complex in any bone forming tissue, and a resultant decrease occurs in the growth rate of long bones in the fetus and newborn infant. It is also deposited in teeth, causing discoloration until mineralisation is completed at age 6. Tetracyclines cross the placenta and are excreted in breast milk, but absorption by infants is negligible..$^{5}$ Doxycycline should not be used in children under 8 years old or in pregnant women. It should also be avoided in lactating women if there is an appropriate alternative.

Mike Starr paediatric infectious diseases physician Royal Children's Hospital Travel Clinic, Royal Children's Hospital, Melbourne, Australia starrm@cryptic.rch.unimelb.edu.au

\section{Croft A. Extracts from "Clinical Excellence": Malaria: pre- vention in travellers. BMJ 2000;321:154-60. (15 July.) \\ 2 Veltri JC, Osimitz TG, Bradford DC, Page BC. Retrospec- tive analysis of calls to poison control centers resulting from exposure to the insect repellent N,N-diethyl-m- toluamide (DEET) from 1985-1989. J Toxicol Clin Toxico 1994;32:1-16 \\ 3 Luxemburger C, Price RN, Nosten F, ter Kuile FO, Chong- suphajaisiddhi T, White NJ. Mefloquine in infants and young children. Ann Trop Paediatr 1996;16:281-6. \\ 4 Nosten F, ter Kuile F, Maelankiri L, Chongsuphajaisiddhi T, Nopdonrattakoon L, Tangkitchot S, et al. Mefloquin prophylaxis prevents malaria during pregnancy: a double- blind, placebo-controlled study. I Infect Dis 1994;169: 595-603 \\ 5 Posner AC, Prigot A, Konicoff NG. Further observations on the use of tetracycline hydrochloride in prophylaxis and treatment of obstetric infections. Antibiot Anm 1954;5:594-8. \\ Homoeopathy may not be effective in preventing malaria}

EDITOR-The homoeopathic principle that like should be cured with like is not always advisable, ${ }^{1}$ as illustrated in this case report.

A 40 year old woman took two holidays a year in tropical countries. After experiencing digestive disorders with conventional prophylactic drugs she decided to seek medical advice from a homoeopath for her forthcoming holiday in Togo. Two homeopathic drugs were prescribed: Ledum palustre 5 CH (Boiron, Sainte-Foy-lès-Lyon, France) as one granule daily and Malaria officinalis 4 CH (Schmidt-Nagel, Meyrin, Switzerland) as a single dose on the day before departure.
Ledum palustre $5 \mathrm{CH}$ can be purchased in any French pharmacy and is usually taken to prevent insect bites or to reduce allergic reactions and pruritus. Malaria officinalis $4 \mathrm{CH}$ is unavailable in France and therefore was bought by mail order. The preparation is taken "against malaria" as the doctor or patient sees fit. It is made from "African swamp water containing impurities, algae and plants as well as mosquito slough, larvae and eggs." Furthermore, "the manufacturer, who has performed no clinical trials on this drug, declines all responsibility regarding its use." No instructions are supplied, and the destination of the journey and duration of the stay are not taken into account.

Five days after returning to France with a fever $\left(39^{\circ} \mathrm{C}\right)$, the patient sought medical advice from her homoeopath. Results of a blood smear test for malaria parasites were negative; haemoglobin concentration was $13.9 \mathrm{~g} / \mathrm{l}$ and platelet count 160000 per $\mathrm{mm}^{3}$. She took homoeopathic drugs with vitamins, and a few days later antibiotic treatment was started. Ten days after the first medical visit she felt worse. Her temperature had risen to $41^{\circ} \mathrm{C}$ and her haemoglobin concentration was $10.6 \mathrm{~g} / \mathrm{l}$ and platelet count 66000 per $\mathrm{mm}^{3}$. She was admitted to hospital, where she was investigated for bacterial infection but not malaria. Four days later she was admitted with neurological disorders to the intensive care unit at this hospital. An emergency search for malaria showed the presence of Plasmodium falciparum (parasitaemia 7\%). For two months she received intensive care for multiple organ system failure due to $P$ falciparum.

This case confirms the inefficacy of homoeopathic drugs for malaria prevention and treatment. ${ }^{2}$ Travellers to tropical countries should use recognised prophylactic drugs.

Pascal Delaunay specialist in parasitology, department of parasitology-mycology delaunay.p@chu-nice.fr

Eric Cua specialist in infectious diseases, department of intensive care

Philippe Lucas specialist in intensive care and cardiology, department of intensive care

Pierre Marty specialist in parasitology and tropical medicine, department of parasitology-mycology University Hospital, BP 3079, 06202 Nice, Cedex 03, France

1 Vickers A, Zollman C. ABC of complementary medicine: homoeopathy. BMJ 1999;319:1115-8.

2 Carlsson T, Bergqvist L, Hellgren U. False safety with homeopathic agents. Swedes became ill with malaria in spite of prophylaxis. Lakartidningen 1995;92:4467-8.

\section{C282Y mutation and type 2 diabetes}

\section{Study was much too small for inferences} to be drawn

Editor-Inconclusive genetic studies should not be published in the BMJ. Once again the journal has published a genetic association study based on a tiny sample of cases and producing scarcely significant results. ${ }^{1}$ It has allowed the authors to claim that they may have identified an important 
risk factor for a common and serious disease, on the basis of only the flimsiest of evidence.

The authors report a study that, owing to its prospective design, was of just 27 subjects who developed diabetes along with 481 others who remained unaffected. They identified the C282Y mutation in the haemochromatosis gene as a predictor for developing diabetes $(\mathrm{P}=0.047)$. Given the very small numbers in the study (with only five subjects carrying the mutation becoming affected), it seems implausible that this $P$ value is even accurate, but it is certainly not small enough to provide any real evidence for this polymorphism being a risk factor for diabetes.

The small number of affected subjects further weakens the conclusions because, as I have argued elsewhere, ${ }^{2}$ results based on small samples are more likely to represent type 1 errors than results from large samples which produce an equivalent $\mathrm{P}$ value. Because genetic risk factors are continuously present throughout life, prospective studies have relatively few advantages; case-control designs are usually to be preferred because of the large number of affected subjects they provide. For a disease as common as diabetes it is ludicrous to draw inferences from only 27 affected subjects.

Publishing this kind of study without appropriately cautious discussion can have a pernicious effect. For example, the authors have been allowed to claim that "the C282Y mutation also predisposes to coronary heart disease." There is practically no evidence to support this. The authors cite a paper of their own, ${ }^{3}$ which is in fact very similar to the current one and reports similarly unimpressive $\mathrm{P}$ values. Once such statements are published many readers will naively accept them rather than being aware that they are in fact highly speculative.

It is ironic that a paper that would have struggled to get into any respectable genetics journal should have been published in a general journal with a high profile and a readership less familiar with the caveats that should apply to this kind of study. The BMJ does medicine a great disservice by giving undue prominence to such inconclusive and flawed work

David Curtis consultant psychiatrist

East London and City Mental Health NHS Trust, Department of Adult Psychiatry, Royal London Hospital, London E1 1BB

Dcurtis@hgmp.mrc.ac.uk

1 Salonen JT, Tuomainen T-P, Kontula K. Role of C282Y mutation in haemochromatosis gene in development of type 2 diabetes in healthy men: prospective cohort study. BMJ 2000;320:1706-7. (24 June.)

2 Curtis D. Defending attacks on statistics. Nature Med 1996;2:4.

3 Tuomainen TP Kontula K, Nyyssonen K, Lakka TA Helio T, Sakn TT, Kontula K, Nyssonen K, Lakka TA, He , Salonen T..ncreased risk of acute in can iers of the hemeche Con:a prospective cohort study in men in eastem Fing Circulation 1999:100:1274-9.

\section{Authors' reply}

EDITOR-Curtis criticises our work showing an association between the C282Y mutation in the haemochromatosis gene and the incidence of type 2 diabetes in 508 men, who were followed up for four years. During follow up 27 men developed diabetes. As we discussed in our paper, this study is small. Consequently, the statistical certainty of the estimate of relative risk (3.5) is rather low, as indicated by the wide confidence interval. The way to proceed in science is that our findings will be retested in further studies. In fact, we will complete an 11 year follow up of our cohort by the end of this year. This will allow us to retest our hypothesis with a larger number of incident cases.

Curtis claims that case-control studies would be preferable in genetic epidemiology. We disagree. Most retrospective casecontrol studies are flawed by the survival and incidence-prevalence biases. Unfortunately, prospective studies are few, but those few have shown that the results from prospective and retrospective studies tend to differ. We believe that it is more important to avoid the biases of retrospective studies than to attempt to enhance power by collecting a large number of cases retrospectively. We consider retrospective case-control studies to be virtually worthless in genetic epidemiology and wish that editors and readers would pay more attention to the study design and the validity of the findings than to large numbers.

Jukka T Salonen professor of epidemiology jukka.salonen@uku.fi

Tomi-Pekka Tuomainen research fellow Research Institute of Public Health, University of Kuopio, Box 1627, 70211 Kuopio, Finland

Kimmo Kontula professor of molecular medicine Department of Medicine, Helsinki University Hospital, 00290 Helsinki, Finland

\section{Asthma after childhood pneumonia}

Microbiological assessment is needed for accurate diagnosis of pneumonia

EDiToR-Clark et al comment that "the cumulative prevalence of asthma after childhood pneumonia is high; therefore careful follow up is recommended to detect new cases." I agree with this sentiment, but I do not believe that they have made an accurate diagnosis of pneumonia; they have not determined a microbiological cause. Without this, consolidation on chest radiography, together with fever and tachypnoea, might be confused with a viral exacerbation of asthma and the radiological features of mucous plugging.

I believe that the authors have highlighted an important message: keep an open mind about radiological and clinical diagnoses of asthma versus pneumonia. I do not think that they have shown an association between pneumonia and asthma.

John Furness paediatric specialist registrar Sunderland Royal Hospital, Sunderland SR4 7TP J.C.Furness@ncl.ac.uk

1 Clark CE, Coote JM, Silver DAT, Halpin DMG. Asthm after childhood pneumonia: six year follow up study. $B M$ J 2000;320:1514-6.

\section{Cumulative prevalence was not best} statistic to use

EDITOR-Clark et al found that of 131 children recruited into their study, 35 had symptoms of asthma or a diagnosis of asthma or received treatment for asthma during six years' follow up. ${ }^{1}$ This is presented as a cumulative prevalence of $45 \%$, which is considerably greater than previous studies have shown. This figure may have resulted from bias in selection of more symptomatic children during recruitment and follow up.

Altogether 93 chest radiographs were reviewed, and it was agreed that 78 showed signs of pneumonia. Thirty five of these cases had "any diagnosis of asthma," had received treatment for asthma, or had high symptom scores. Thirty five out of 131 represents a cumulative prevalence of $27 \%$ considerably less than the $45 \%$ quoted.

Children not included in the follow up may not have had chest radiography because they had milder symptoms; may not have had changes in the chest radiograph but still have had pneumonia; or may later have been entirely symptom free and so not have elected to attend any follow up. Those initially recruited may have attended hospital after asthma selected them for presenting with more severe symptoms.

The measurement of cumulative prevalence is not the best statistic to use in this situation as half of the children studied were aged under 4 , an age when making a definitive diagnosis of asthma is difficult. Many children wheeze or cough as a result of viral respiratory tract infection ${ }^{2}$ or because they were born with intrinsically smaller airways that are more easily obstructed. ${ }^{3}$ Most of these children will not retain a diagnosis of asthma, yet in this study they are included with those who do.

Measuring point prevalence or using a measure of morbidity that examines data over six months or a year, such as a symptom diary or the international study of asthma and allergy in childhood questionnaire, might have resolved this issue. The epidemiological study of Martinez et al found that $48.5 \%$ of children wheezed during their first six years but only $13.7 \%$ of these were wheezing at 3 and still at 6 years. ${ }^{4}$ These figures show that there is a high frequency of transient non-asthmatic airways symptoms in younger children.

Further longitudinal studies following up children in their earliest years are needed to clarify which wheezing children will retain or attain a diagnosis of asthma in later childhood and adulthood.

Simon Fearby clinical research fellow

J B Clough senior lecturer in child health jbc@soton.ac.uk

Department of University Child Health, Mail point 803, Southampton General Hospital, Southampton SO16 6YD

1 Clark EC, Coote JM, Silver DAT, Halpin DMG. Asthm after childhood pneumonia: six year follow up study. BMJ 2000;320:1514-6. (3 June.)

2 Pattemore PK, Johnston SL, Bardin PG. Viruses as precipitants of asthma symptoms. I. Epidemiology. Clin Exp Allergy 1992;22:325-36. 
3 Martinez FD, Morgan W, Wright AL, Holberg C, Taussig LM, GHMA Personnel. Diminished lung function as a predisposing factor for wheezing respiratory illness in infants. NEngl J Med 1988;319:1112-7.

4 Martinez FD, Wright AL, Taussig LM, Holberg CJ, Halonenen M, Morgan WJ, et al. Asthma and wheezing in the first six years of life. N Engl J Med 1995;332:133-8.

\section{Authors' reply}

EDITOR-Furness believes that we have highlighted an important message. The diagnosis of pneumonia in children can be difficult; indeed, two children in the cohort that we studied presented via the surgical services, having been referred with abdominal pain. Pneumonia, however, is a clinical and radiological diagnosis, and we went to some lengths in reviewing the radiographs to validate this diagnosis. Many children will never have a microbiological diagnosis made, even in studies that set out to do this.

Our message is that these patients were diagnosed, appropriately, as having pneumonia and not asthma, and that many of them had or will develop asthma. Unless this is thought about the diagnosis will be missed.

Fearby and Clough have speculated that our figures are biased by the selection of children who were more ill. There was no evidence that this was the case. The cohort whom we presented represent those children in whom the admission radiograph could be traced and two independent radiologists agreed that it showed signs of pneumonia. In fact, we had the original $x$ ray report and follow up information for 122 children (93\% of the original cohort). The cumulative prevalence of asthma was $47 \%$ (57 cases), or $44 \%$ of the original cohort, which supports our assertion that this group contained a high number of children who were subsequently found to be asthmatic. Our finding that there were significant symptom scores in untreated as well as treated asthmatic children suggests that these children were not simply the transiently wheezy non-asthmatic children that they suggest.

We agree with Fearby and Clough's call for more detailed large longitudinal studies to help predict which children may carry the highest risk of developing asthma.

C E Clark general practitioner

Mid Devon General Practice, Witheridge, Devon

EX16 8AH

ceclark@sol.co.uk

J M Coote consultant radiologist

D A T Silver consultant radiologist

D M G Halpin consultant physician

Royal Devon and Exeter Hospital (Wonford),

Exeter EX2 5DW

\section{Suicidal ideation in patients with rheumatoid arthritis}

\section{Research may help identify patients at high risk}

EDITOR-The finding of Carson et al-that depression associated with progressive physical (neurological) illness may lead to suicidal ideation-has important clinical implications and may be generalisable. Rheumatoid arthritis, the most prevalent chronic inflammatory musculoskeletal disease, ${ }^{2}$ has been associated with several negative psychological outcomes, including depression

Our ongoing studies indicate that almost $11 \%$ of hospital outpatients with rheumatoid arthritis (13 out of 123; 95\% confidence interval $5 \%$ to $16 \%$ ) experience suicidal ideation, as detected by the Nottingham health profile. ${ }^{4}$

At first glance, patients with longstanding disease (of more than four years' duration) seem more likely to report suicidal ideation $(12 \%)$ than those with early rheumatoid arthritis (of less than two years' duration) $(7 \%)$. Sex may also play a part, with $14 \%$ of female patients reporting suicidal ideation compared with only $3 \%$ of male patients. However, clinical depression detected by the hospital anxiety and depression scale, ${ }^{5}$ is the most important factor; $30 \%$ of those reporting depression also experience suicidal ideation, a significantly higher proportion than the $7 \%$ seen in those who are not depressed $\left(\chi^{2}=9.54, \mathrm{P}<0.01\right)$.

This is confirmed by binary logistic regression of suicidal ideation, used to examine simultaneously the predictive value of age, sex, duration of rheumatoid arthritis, clinical anxiety, and depression. In this analysis only the presence of clinical depression was predictive of suicidal ideation (odds ratio $4.47, \mathrm{P}<0.05$ ).

These findings support the suggestion by Carson et al that mental health assessment of physically ill patients should form part of routine clinical evaluation, particularly in chronic illness. Further research may help identify a demographic, physical and psychosocial profile that could predict patients at high risk of developing suicida ideation.

Gareth J Treharne health psychology postgraduate research student

gjt884@bham.ac.uk

Antonia C Lyons lecturer in health psychology a.c.lyons@bham.ac.uk

George D Kitas consultant rheumatologist g.d.kitas@bham.ac.uk

University of Birmingham, Birmingham B15 2TT

1 Carson AJ, Best S, Warlow C, Sharpe M. Suicidal ideation tive study. BMJ 2000;320:1311-2. (13 May.)

2 Newman SP, Fitzpatrick R, Revenson TA, Skevington S, Williams G, Understanding rheumatoid arthritis. London: Routledge, 1996.

Pincus T, Gifth J, Pearce S, Isenberg D. Prevalence of selfPince I, Searce S, Isenberg D. Prevalence of selreported depression in patients with rheumatoid arthritis.
BrJ Rheumatology 1996;35:879-83.

4 Hunt SM, McEwan J, McKenna S. Measuring health status. New Hampshire: Croom Helm, 1986.

5 Zigmond AS, Snaith RP. The hospital anxiety and depresZigmond AS, Snaith RP. The hospital anxiety and
sion scale. Acta Psychiatr Scand 1983;67:361-70.

\section{Natural course of suicidal ideation and} treatment efficacy need to be known

EDITOR-Government white papers (Health of the Nation and Our Healthier Nation) and the national service framework for mental health have set targets for reducing suicide rates. The paper of Carson et al reporting a $9 \%$ prevalence of suicidal ideation in outpatients attending neurology clinics was timely. ${ }^{1}$ The authors used a tight definition of suicidal ideation-patients had to have thought about active plans for committing suicide which is much closer to suicidal intention than ideation and thus their findings are important. We reported a prevalence of up to $36 \%$ in elderly inpatients who were acutely medically ill. ${ }^{23}$ Furthermore, physical illness is a well recognised risk factor for suicide.

Carson et al advocate screening for suicidal ideation by general practitioners and other specialists and referral to psychiatrists for treatment. ${ }^{1}$ Before recommending such a course of action, using an ideal evidence based approach, two important pieces of evidence are necessary.

Firstly, information on the natural course of suicidal ideation through longitudinal follow up studies is needed. If the suicidal ideation (and associated depression) improves with treating the physical illness then the role of psychiatric services may be less important.

Secondly, information on the efficacy of intervention from psychiatric services in reducing suicidal ideation and associated mental illness is unestablished.

We retrospectively reanalysed data from our single blind, randomised and controlled study of early identification of depression and pragmatic intervention by psychogeriatric consultation. ${ }^{4}$ The original one year study with 47 subjects showed that the intervention was not effective in improving the depression. There were many potential explanations (including methodological) for this negative finding. Retrospective analysis on the efficacy of this intervention on suicidal ideation showed that the suicidal ideation measured on the MontgomeryAsberg depression rating scale ${ }^{5}$ improved at 10 weeks' follow up. Suicidal ideation measured on other scales did not improve.

Pragmatically, patients who are medically ill and have suicidal ideation could be considered to need treatment both by medical specialists and psychiatrists. However, there are clear implications for distribution and concentration of resources. Should more resources be targeted for the medical specialties (to concentrate efforts on the treatment of medical illness, which may also improve suicidal ideation) or for psychiatry (to develop liaison psychiatric services, for example)? This question can be answered only if more detailed data on the natural course of suicidal ideation in these patients and the efficacy of intervention by psychiatric services are available; there is an unequivocal need for such studies.

Tara Collinge specialist registrar in psychiatry Ajit Shah consultant psychiatrist

a.k.shah@ic.ac.uk

John Connolly Unit, Ealing, Hammersmith and Fulham Trust, Middlesex UB1 3EU

1 Carson AJ, Best S, Warlow C, Sharpe M. Suicidal ideation neurology clinic: prospective study. BMJ. 2000;320:1311-2.

2 Shah A, Dighe-Deo D, Chapman C, Phongsathorn V, George C, Bielawski C, et al. Suicidal ideation amongst acutely , Bedically ill and continuing care inpatients. Ageing and Mental Health. 1998;2:3005. 
3 Shah A, Hoxey K, Mayadunne V. Suicidal ideation in acutely medically ill elderly inpatients: prevalence, correlates and longitudinal stability. International Journal of Geriatric Psychiatry 2000;15:162-9.

4 Shah A, Odutoye K, De T. Depression in acutely medically ill elderly inpatients: a pilot study of early identification and intervention by formal psychogeriatric consultation. JAffect Disord (in press).

5 Montgomery S, Asberg M. A new depression scale designed to be sensitive to change. $B r J$ Psychiatry. 1979;134:382-9.

\section{Mental Welfare Commission's role needs to be explained further}

EDitor-Alexander et al asked Scottish consultant psychiatrists about the helpfulness of various proceedings and events after the suicide of patients. ${ }^{1}$ The intervention of the Mental Welfare Commission was found to be unhelpful and is referred to, along with other enquiries, as contributing to a blame culture.

Although this undoubtedly accurately reports views expressed, it gives a misleading impression of the commission's role and practice. At one level, the statement is unexceptional; after all, the commission was not set up to be helpful to psychiatrists but to protect the welfare of patients. To associate the commission's involvement with the fostering of a blame culture, however, is a mistake.

The commission has a statutory duty to protect the welfare of those vulnerable through mental disorder, and to enquire into possible deficiency in care. In carrying out this duty it seeks reports on patients who commit suicide when in contact with mental health services or who have recently been in contact.

It receives about 100 reports each year, and these are considered at meetings of the commission. In a minority of cases, there may be follow up questions to obtain additional information. Relatives sometimes express concerns. In most cases the commission finds no concern about deficiency in care and carries out no enquiry. In a small number of cases, enquiry may be needed into deficiency in individual practice or service provision or both. Such infrequent enquiries are conducted in a spirit of finding solutions rather than culprits. The commission is as concerned as anyone else about the negative effects of a blame culture, which is often encouraged by the media. It does not wish to be tarred by the media's brush.

In Scotland, the Millan Committee is currently reviewing the Mental Health (Scotland) Act 1984, and, as part of that, the role of the Mental Welfare Commission. The Royal College of Psychiatrists in Scotland, in its response to the second consultation, has said that the Commission should undertake investigations into complaints about health care more frequently, and that it should have an independent power to publish its deficiency in care reports and more power to enforce its recommendations. Maybe it is human to support having a watchdog but to feel uncomfortable when it turns in your direction, especially in the aftermath of a distressing experience like suicide.

James A T Dyer director

Mental Welfare Commission for Scotland, Argyle House, Edinburgh EH3 9SH

JDyer@mwcscot.co.uk

1 Alexander DA, Klein S, Gray NM, Dewar IG, Eagles JM. Suicide by patients: questionnaire study of its effect on consultant psychiatrists. BMJ 2000;320:1571-4. (10 June.)

\section{Early environmental factors may have role in both Crohn's disease and gastric carcinoma}

EDITOR-Leon and Davey Smith report a geographical correlation between mortality from gastric cancer and infant mortality. ${ }^{1} \mathrm{We}$ have reported a similar but opposite relation between mortality at birth and incidence of Crohn's disease, the incidence of the disease being highest in those countries where infant mortality is lowest.

We believe that this reflects improvement in hygienic conditions with time, which, once reaching a threshold, become a risk for Crohn's disease. This may be due to a changing exposure pattern to infectious agents in early life-at an older age and lower dose. This is supported by studies of family composition that suggest that having no older siblings is a risk factor for developing Crohn's disease. ${ }^{3}$ In contrast, infection with Helicobacter pylori has been inversely correlated with inflammatory bowel disease in some studies ${ }^{4}$ and is a marker for overcrowding, large families, and high birth order as well as being a gastric carcinogen.

When mortality from gastric cancer (obtained from the same sources as data in Leon and Davey Smith's study) was correlated with the incidence of Crohn's disease (the largest published study with age standardised data available for each country from the past 15 years), a strong inverse relation was found. This is apparent for both sexes and across 26 countries (for males $r^{2}=0.35, \mathrm{P}=0.003$; for females $r^{2}=0.39$, $\mathrm{P}=0.002)$. This association was not seen when mortality from cervical, prostate, or lung cancer was compared with incidence of Crohn's disease and was also not present for ulcerative colitis (figure).

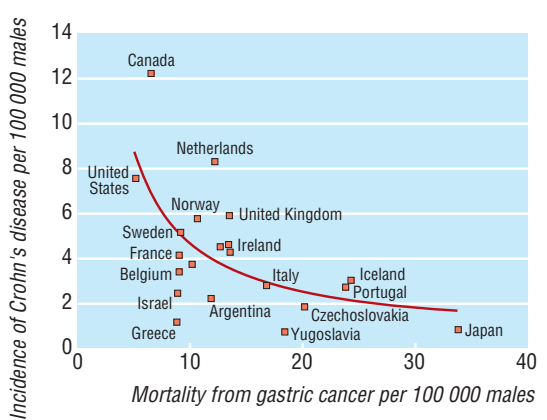

Incidence of Crohn's disease and mortality from gastric cancer among males worldwide
One possible source of confounding is that falling mortality from gastric cancer will indicate improvements in socioeconomic and healthcare factors related to survival rather than simply incidence of gastric cancer. Where comparable figures were available, however, incidence of gastric cancer did correlate well with mortality in this study $\left(r^{2}=0.76, \mathrm{P}<0.0001\right)$.

Notwithstanding this and other limitations of ecological studies, ${ }^{5}$ we believe that this study adds support for the role of contrasting early environmental influences in the aetiology of both Crohn's disease and gastric carcinoma. Patterns of early infection and colonisation (although by different agents) are likely to be important in the aetiology of both diseases.

Danielle L Morris Wellcome training fellow in epidemiology

Wisemail@Compuserve.com

Scott M Montgomery principal research fellow in epidemiology

Inflammatory Bowel Disease Study Group, Royal Free and University College Hospital Medical School, London NW3 2PF

1 Leon DA, Davey Smith G. Infant mortality, stomach cancer, stroke, and coronary heart disease: ecological cancer, stroke, and coronary heart dis
analysis. BMJ 2000;320:1705-6. (24 June.)

2 Montgomery SM, Pounder RE, Wakefield AJ. Infant mortality and the incidence of Crohn's disease. Lancet 1997;349:472-3

3 Montgomery SM, Twamley SI, Morris DL, Pounder RE, Wakefield AJ. Birth order influences IBD risk and phenotype. Gastroenterology 1999 A2063.

4 Halme L, Rautelin H, Leidenius M, Kosunen TU. Inverse correlation between Helicobacter pylori infection and inflammatory bowel disease. J Clin Pathol 1996;49:65-7.

5 Forman D, Goodman KJ. The epidemiology of stomach cancer: correlating the past with the present $B M J$ 2000;320:1682-3.

\section{The future of gambling in Britain}

EDITOR-In the light of the forthcoming review of gambling legislation, Volberg considers the future of gambling in Britain, and hypothesises that the increasing availability of gambling opportunities will lead to an increased prevalence of problem gamblers. ${ }^{1}$ She notes the lack of baseline data on gambling in Britain before the National Lottery was introduced and argues that future changes in gambling should be monitored over time.

Two days before the publication of this editorial, the National Centre for Social Research published the results from the first national survey of gambling behaviour in Britain. ${ }^{2}$ The survey (of 7000 people) found that $72 \%$ of the population participates in at least one gambling activity each year and that $65 \%$ play the National Lottery. The survey estimates that $0.8 \%$ of the population are problem gamblers $(95 \%$ confidence interval $0.6 \%$ to $1.0 \%$ ). This equates to about a third of a million people.

Volberg argues that the National Lottery is likely to increase women's participation in gambling and therefore to increase the proportion of female problem gamblers. The British survey found that men are more likely to participate in most types of gambling: fruit machines (20\% men, $8 \%$ 
women), private betting ( $17 \%$ men, $6 \%$ women), horse races ( $18 \%$ men, $9 \%$ women), and the football pools (13\% men, 5\% women). However, participation in the lottery is only slightly higher among men (68\% men, $62 \%$ women). The only activity that women are more likely to play is bingo (10\% women, $5 \%$ men). As well as being more likely to gamble, a higher percentage of men are problem gamblers $(1.3 \%$ men, $0.5 \%$ women).

As Volberg points out, the lack of data on gambling in Britain before the National Lottery means that it is not possible to assess its impact. But it is not just the lottery that is changing the face of gambling. A notable activity for future concern is internet gambling, currently done by only $1 \%$ of the British population but a figure that is likely to increase dramatically over the next few years. Now that there are reliable data on gambling and problem gambling in Britain, the impact of future changes in legislation should be monitored. Adequate funding of prevention and treatment programmes is necessary to minimise the harm that such changes may have.

Kerry Sproston senior researcher

National Centre for Social Research, Edinburgh

EH1 1LZ

K.Sproston@natcen.ac.uk

Bob Erens research director

National Centre for Social Research, London ECIV 0AX

Jim Orford professor of clinical and community psychology

School of Psychology, University of Birmingham and Northern Birmingham Mental Health NHS Trust, Birmingham B15 2TT

1 Volberg RA. The future of gambling in Britain. $B M$ 2000;320:1556. (10 June.)

2 Sproston K, Erens B, Orford J. Gambling behaviour in Britain: results from the gambling prevalence survey. London: National Centre for Social Research, 2000).

\section{Issues in long term care will not disappear}

EDITOR-I am writing in response to the editorial by Dixon and Dewar on the NHS plan. ${ }^{1}$ The government has published its response to the recommendations of the Royal Commission on Long Term Care. ${ }^{23}$ It has accepted in full or in slightly modified form 23 of the 24 recommendations of the royal commission. It has not fully accepted the main recommendation but is proposing to fund nursing care in nursing homes.

When discussing funding for long term care, the royal commission set out a series of options, including disregarding the value of the home for the first three months, changing the limits on the means test, and funding nursing care. All of these were subsumed in the main recommendation. The government has accepted all the options on funding except for the main recommendation. Two important consequences result from the government's failure to accept the main recommendation of the royal commission.
The current inequity in the system will continue. This can be exemplified by comparing an elderly person who develops cancer, whose treatment, hospital, and, if necessary, terminal care is fully funded by the NHS, with an elderly person who develops Alzheimer's disease, who will often require a considerable amount of care and supervision, but not usually nursing care, and who will continue to have to fund this by using all available resources, including the value of the home. The government's statement, quoted from the note of dissent that the funding necessary to implement the royal commission's recommendation would not result in any improvement in services, must be read in the context of this continuing inequity. This type of diagnosis related lottery of care should be unacceptable in a civilised and wealthy country.

Funding nursing care but not personal care will introduce a new perverse incentive. Under the proposal, nursing homes will receive a subsidy of about $£ 100$ per week. This will mean that nursing homes, which are intended for the most dependent, will be slightly cheaper than residential homes, intended for the less dependent, and also probably cheaper than some packages of intensive domiciliary care. Thus, two fundamental principles of long term care-that it should be delivered in the person's own home, and that it should be of no greater intensity than is necessary-will be directly opposed by financial pressures on purchasers of care.

These issues will not disappear. It would be best if they were addressed now as part of the government's comprehensive package of NHS reforms. ${ }^{4}$

Robert W Stout professor of geriatric medicine Department of Geriatric Medicine, Queen's University Belfast, Whitla Medical Building, Belfast BT9 7BL

r.stout@qub.ac.uk

1 Dixon J, Dewar S. The NHS plan. BMJ 2000;320:31506. (5 August.)

2 The NHS plan. The government's response to the Royal Commission on Long Term Care. London: Stationery Office, 2000.

3 Roval Commission on Long Term Care. With respect to old age. London: Stationery Office, 1999.

4 The NHS plan. A plan for investment. A plan for reform

London: Stationery Office, 2000.

\section{Patients' views on cost effectiveness of drugs are important}

EDIToR-The report by the National Institute for Clinical Excellence on the use of proton pump inhibitors for treating dyspepsia sets the target of at least a $15 \%$ reduction in prescribing of these drugs in England and Wales, with consequent savings of $£ 40 \mathrm{~m}$ $£ 50 \mathrm{~m}$ a year.

We carried out a qualitative study of patients' and general practitioners' views of long term use of proton pump inhibitors. Patients commonly expressed concerns about long term use of the drugs but said that they could not manage without them. ${ }^{23}$ Most of the general practitioners were already trying to reduce their prescribing, much in line with the institute's guidelines. They did not consider themselves to be prescribing proton pump inhibitors profligately or inappropriately. Recognising their patients' need for an effective means of controlling severe and unpleasant symptoms, they often found it difficult to get patients to stop taking the drugs or to take a reduced dose.

Cost is an important concern, but the general practitioners in our study considered that their primary obligation was to respond effectively to their patients' needs. Clinical concerns outweighed the price of treatment. The poor fit between the severity of symptoms and the underlying pathology of gastric disorders is well established. Regardless of diagnosis, many patients said that they could not manage without proton pump inhibitors to control their symptoms.

The report by the National Institute for Clinical Excellence does not focus on what is most important to patients-that is, effective relief from painful and debilitating symptoms, and the ability to fulfil adequately their economic and social roles and obligations. Pressure to reduce costs is likely to raise the prescribing threshold for proton pump inhibitors. The legitimacy of patients' need for health care is being arbitrarily redefined in terms of cost considerations, and without any open consultation with patients.

We argue that patients' perspective on the cost effectiveness of proton pump inhibitors (and other medicines) should feature prominently in any discussion of prescribing policy. Patients have no control over the cost of proton pump inhibitors, and those in our study had no other means of effectively treating their discomfort. Patients, doctors, and health service administrators all support the aim of avoiding unnecessary prescribing and medicine taking, and eliminating unnecessary expenditure in the NHS. But patients' evaluation of the benefit to be derived from treatment, and the value for money that this represents, must be an important consideration in prescribing policy.

Kristian Pollock concordance research fellow k.pollock@keele.ac.uk

Janet Grime concordance research fellow Department of Medicines Management, Keele University, Keele, Staffordshire ST5 5BG

1 National Institute for Clinical Excellence. Guidance on the use of proton pump inhibitors in the treatment of dyspepsia.

2 Pollock K, Grime J, Blenkinsopp A. Proton pump inhibitors: perspectives of patients and their GPs. Keele: Keele University Department of Medicines Management, 1998.

3 Pollock K, and Grime J. Strategies for reducing the prescribing of proton pump inhibitors (PPIs): patient selfregulation of treatment may be an under-exploited resource. Soc Sci Med (in press).

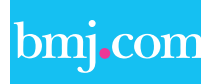

\section{Rapid responses}

Correspondence submitted electronically is available on our website 